\title{
Quantitative in Vivo Receptor Binding IV: Detection of Muscarinic Receptor Down-Regulation by Equilibrium and by Tracer Kinetic Methods*
}

\author{
K. A. Frey ${ }^{1,2,3,4}$, B. Ciliax ${ }^{2}$, and B. W. Agranoff ${ }^{3}$
}

(Accepted April 22, 1991)

\begin{abstract}
Newly-developed methods for estimation of in vivo binding to neurotransmitter receptors should enable the detection and quantification of physiologic or pathologic changes in receptor numbers. In the present study, both equilibrium and kinetic experimental strategies for in vivo muscarinic receptor determination were applied to the detection of receptor changes induced by chronic inhibition of acetylcholinesterase in the rat. Following one week of treatment, in vitro receptor autoradiography utilizing $\left[{ }^{3} \mathrm{H}\right]$ scopolamine revealed significant losses of muscarinic binding in the cerebral cortex, hippocampus, striatum and in cranial nerve motor nuclei. The in vivo distribution of $\left.{ }^{3} \mathrm{H}\right]$ scopolamine, following infusion to approach equilibrium binding in the brain, revealed reductions in binding which paralleled the pattern and magnitude of changes detected in vitro. A simplified tracer kinetic estimation following bolus injection of the ligand also detected substantial reductions in forebrain muscarinic receptor binding. These results indicate the feasibility of detecting receptor changes underlying neuropathologic conditions in vivo, and suggest that either equilibrium or kinetic experimental approaches may be extended to clinical research applications with the use of positron or single-photon emission tomography.
\end{abstract}

KEY WORDS: Scopolamine; in vivo binding, muscarinic receptor, PET (positron emission tomography); autoradiography.

\section{INTRODUCTION}

New methods are being explored for their potential to allow noninvasive in vivo measurements of human brain neurotransmitter receptors, enzymes, or other ligand binding sites (1). Cerebral radioligand distributions may be imaged with the use of positron emission to-

\footnotetext{
${ }^{1}$ Departments of Internal Medicine (Division of Nuclear Medicine) and ${ }^{2}$ Neurology and ${ }^{3}$ The Mental Health Research Institute, The University of Michigan, Ann Arbor, MI 48109.

${ }^{4}$ Address reprint requests to: K. A. Frey, M.D., Ph.D., BIG 412/ 0028 University Hospital, 1500 E. Medical Center Dr., Ann Arbor, MI 48109-0028. Telephone: (313) 936-5387 Fax: (313) 936-8182

* Special issue dedicated to Dr. Louis Sokoloff.
}

mography (PET) or single-photon emission computed tomography (SPECT), and may be employed for measurement of regional binding site densities with appropriate combinations of tracer molecules and experimental designs. As an example, prior research in experimental animals has indicated the feasibility of imaging muscarinic cholinergic receptor density on the basis of the distribution of $\left[{ }^{3} \mathrm{H}\right]$ scopolamine in vivo (2-4).

Labeled scopolamine demonstrates desirable properties for in vivo studies including high specificity for binding to the muscarinic receptor, clear distinction of specific from nonspecific binding, and absence of labeled nonvolatile metabolites in the brain (2). Volatile metabolites are observed in the brain following injection 
of $\left[\mathrm{N}\right.$-methyl $\left.{ }^{3} \mathrm{H}\right]$ scopolamine, presumably originating from peripheral metabolism of the tracer. However, they are easily removed by drying and do not interfere with accurate quantification of brain ligand distribution.

Two differing experimental protocols have each provided estimates of scopolamine binding in the intact rat brain. The first method employs equilibrium analysis following maintenance of a constant, saturating ligand concentration $(2,3)$. This procedure results in a static regional distribution of ligand which corresponds to muscarinic receptor binding with minor contributions from the presence of nonspecific ligand binding and free ligand in the tissue. The second method makes use of kinetic compartmental analysis following bolus injection of a tracer dose of $\left[{ }^{3} \mathrm{H}\right]$ scopolamine (4). In this instance, the time-courses of regional brain and arterial plasma tracer are required for estimation of receptor binding. These data may be collected at multiple time points from individual subjects with the use of PET. However, in experiments employing small animals, the data must be compiled from invasive measurements on groups of subjects killed at varying post-injection intervals. A simplified approach to kinetic binding estimation which requires independent knowledge or measurement of the regional cerebral capillary permeability-surface area product for the tracer and of regional cerebral blood flow has been previously proposed (4). This method should allow binding estimates from a single observation of ligand distribution at a relatively long post-injection interval, when contribution from nonspecific binding is negligible.

An important aspect of development and evaluation of new radioligand methods is the ability to detect alterations in receptor binding which might arise in experimental applications. In the present studies, both the equilibrium and tracer kinetic experimental approaches to estimation of $\left[{ }^{3} \mathrm{H}\right]$ scopolamine binding are applied to measurements of receptor down-regulation following chronic inhibition of acetylcholinesterase.

\section{EXPERIMENTAL PROCEDURE}

Drug Treatment. Chronic inhibition of acetylcholinesterase was achieved by daily i.m. injection of diisopropylfluorophosphate (DFP) suspended in olive oil. Male Sprague-Dawley rats weighing between 180 and $200 \mathrm{~g}$ were treated according to the following dose schedule: $1.5,1.0,1.0,0.5,0.5$, and $0.5 \mu \mathrm{g} \mathrm{DFP} / \mathrm{kg}$ on days 1 to 6 of treatment, respectively. Receptor binding experiments were performed 18 to 30 $\mathrm{hr}$ following the last treatment. Acute blockade of muscarinic receptors was produced by i.v. injection of atropine sulfate, $50 \mathrm{mg} / \mathrm{kg}, 5 \mathrm{~min}$ prior to in vivo binding studies.

Equilibrium Scopolamine Binding In Vivo. Equilibrium scopolamine binding to the muscarinic receptor in vivo was determined as described previously $(2,3)$. The method employed results in equil- ibration of cerebral receptors with a saturating (approximately $20 \mu \mathrm{M}$ ) arterial plasma concentration of ligand, permitting regional estimates of receptor numbers from individual subjects. In brief, a bolus followed by a continuous infusion of $\left[{ }^{3} \mathrm{H}\right] \mathrm{scopolamine}(15 \mathrm{mCi} / \mathrm{kg}$ total dose) were administered i.v. to produce a constant arterial concentration of tracer for $240 \mathrm{~min}$. At the, end of the infusion, animals were killed and brains were frozen in crushed dry ice.

Coronal $20 \mu \mathrm{m}$ thick sections were prepared in a cryostat and mounted on microscope slides. Sets of three slides, each containing duplicate sections, were obtained at intervals throughout the brain. The first of each group was rapidly dessicated on a hotplate at 60 to $70^{\circ} \mathrm{C}$ for determination of total in vivo binding. Sections on the subsequent two slides were thaw-mounted and allowed to dry at room temperature. One was used for determination of specific in vivo binding by washing in phosphate-buffered saline containing EDTA (PBS: $\mathrm{NaCl}-124 \mathrm{mM}, \mathrm{KCl}-2.7 \mathrm{mM}, \mathrm{Na}_{2} \mathrm{HPO}_{4}-7.7 \mathrm{mM}, \mathrm{KH}_{2} \mathrm{PO}_{4}-1.5$ $\mathrm{mM}$, EDTA - $1 \mathrm{mM}, \mathrm{pH} \mathrm{7.4)}$ at $4^{\circ} \mathrm{C}$ twice for $5 \mathrm{~min}$, followed by a brief dip in $4^{\circ} \mathrm{C}$ distilled $\mathrm{H}_{2} \mathrm{O}$ to remove excess salts and air drying. This procedure had been shown to reduce nonspecific binding without loss of specific binding in preliminary in vitro binding assays to intact tissue sections. The final slide in cach group was processed for in vitro determination of muscarinic receptors by pre-washing in PBS for 5 min, incubation in PBS containing a saturating concentration of $\left[{ }^{3} \mathrm{H}\right]$ scopolamine $(10 \mathrm{nM})$ for $30 \mathrm{~min}$ at $24^{\circ} \mathrm{C}$, followed by washing for $10 \mathrm{~min}$ at $4^{\circ} \mathrm{C}$ and air drying.

Autoradiograms were generated by apposing the slide-mounted tissue to tritium-sensitive X-ray film (Ultrofilm- ${ }^{3} \mathrm{H}$, LKB, Gaithersburg, MD) for 14 days. Following film development, regional brain isotope concentrations were estimated by computer-assisted densitometry (MCID system, Imaging Research, St. Catherines, Ontario, Canada). Film densities overlying brain tissue were compared with those from calibrated radioactive standards, allowing estimation of apparent tissue radioactivity (5).

Kinetic Scopolamine Binding In Vivo. It has been proposed following tracer kinetic studies that the distribution of $\left[{ }^{3} \mathrm{H}\right]$ scopolamine at a long interval (time $t=\tau$ ) following bolus i.v. injection is related to the regional availability of muscarinic receptors (ref 4, equation 31):

$$
\mathrm{C}_{\mathbf{T}}(\tau)=\frac{\left[\mathrm{k}_{3} f\left(1-\mathrm{e}^{\mathrm{PS} / /}\right)\right.}{\left[\mathrm{k}_{3}+f\left(1-\mathrm{e}^{-\mathrm{PS} / f}\right)\right]} \int^{\tau} \mathrm{C}_{\mathrm{A}}(t) \mathrm{d} t
$$

where $\mathrm{C}_{\mathrm{T}}$ and $\mathrm{C}_{\mathrm{A}}$ are the regional tissue and the arterial concentrations of ligand, $f$ represents cerebral blood flow, PS represents the local cerebral capillary permeability-surface area product, and $k_{3}$ represents the rate of ligand binding to the muscarinic receptor. The relationship between receptor availability and $k_{3}$ is described by:

$$
\mathrm{k}_{3}=\mathrm{k}_{\mathrm{a}} \mathrm{R}
$$

where $k_{\mathrm{a}}$ is the bimolecular receptor-ligand association rate constant and $\mathrm{R}$ represents the free tissue receptor concentration.

This simplified calculation of receptor binding following bolus administration of trace doses of $\left[{ }^{3} \mathrm{H}\right]$ scopolamine was applied in animals following chronic cholinesterase inhibition and following acute atropine treatment, the latter to verify the specificity of the simplified method to muscarinic receptor availability.

Femoral arterial and venous catheters were inserted in rats under light diethyl ether anesthesia. Following a $2 \mathrm{hr}$ recovery period, binding studies were initiated by bolus i.v. injection of $100 \mu \mathrm{Ci}$ of $\left[{ }^{3} \mathrm{H}\right]$ scopolamine, and simultaneously beginning continuous arterial blood withdrawal into a heparinized $1 \mathrm{ml}$ syringe at approximately 0.0067 $\mathrm{ml} \mathrm{min}{ }^{-1}$ using an infusion/withdrawal pump (Harvard Apparatus, South Natick, MA). The possibility of ex vivo metabolism of the 
ligand in the blood sample was minimized by packing the withdrawal syringe in ice. At the end of a $90 \mathrm{~min}$ distribution period, cerebral blood flow was determined by i.v. injection of 20 to $50 \mu \mathrm{Ci}$ of $\mathrm{N}, \mathrm{N}, \mathrm{N}^{\prime}$,trimethyl- $\mathrm{N}^{\prime}$-(2-hydroxy-3-methyl-5-[123I]iodobenzyl)-1,3-propanediamine ([123I]HIPDM) and simultaneous withdrawal of a second arterial blood sample at $0.21 \mathrm{ml} \mathrm{min}{ }^{-1}$ for $45 \mathrm{sec}(6,7)$. Cardioplegia was then induced by i.v. injection of $\mathrm{KCl}$, arterial sampling was discon. tinued, and animals were rapidly killed by decapitation.

Brains were dissected, and samples of the cerebral cortex, hip. pocampus, striatum and cerebellum were weighed on an analytical balance and dispersed by sonication in $1 \mathrm{ml}$ of ethanol. Samples were then evaporated to dryness under vacuum to remove volatile ${ }^{3} \mathrm{H}$, and were reconstituted by addition of $100 \mathrm{H}$ of $\mathrm{H}_{2} \mathrm{O}$ prior to the addition of 200 ul of a tissue solubilizer (Soluene-350, Packatd Instruments, Downcts Grove, IL). The ${ }^{123}$ I content of the samples was determined in a gamma counter within $24 \mathrm{hr}$ of the study. Sample ${ }^{3} \mathrm{H}$ contenl was determined one week later, after decay of the ${ }^{123} \mathrm{I}(\mathrm{t} 1 / 2=13.3 \mathrm{~h})$, by addition of $1.8 \mathrm{ml}$ of scintillation fluid (ACS, Amersham, Arlington Hts., IL) followed by liquid scintillation spectroscopy.

The integrated arterial concentration of $\left[{ }^{3} \mathrm{H}\right]$ scopolamine during the 90 min distribution period was calculated from the volume of blood withdrawn $(V)$, the time of withdrawal $(\tau)$, and the plasma concentration of authentic ligand in the sample:

$$
\int_{0}^{\tau} \mathrm{C}_{\mathrm{A}}(t) \mathrm{d} t=\overline{\mathrm{C}_{\mathrm{A}}} \times V \times \tau
$$

where $\overline{\mathrm{C}_{\mathrm{A}}}$ is the average concentration of unmetabolized $\left[{ }^{3} \mathrm{H}\right]$ scopolamine over the interval of observation, as may be determined from the continuously-acquired blood sample. The nonvolatile ${ }^{3} \mathrm{H}$ plasma activity was determined by scintillation counting of duplicate $10 \mu \mathrm{l}$ samples following drying at $60^{\circ} \mathrm{C}$. The fraction of nonvolatile activity corresponding to unmetabolized $\left[{ }^{3} \mathrm{H}\right]$ scopolamine was determined in parallel by thin-layer chromatography on silica gel with a tetrahydrofurandiisopropylethylamine 95:5 mobile phase (2).

Regional cerebral blood flow was calculated from the tissue and second blood sample concentrations of ${ }^{123}$ I]HIPDM using the indicator fractionation method (8) as described by Van Uitert and Levy (9):

$$
f=\frac{\text { (Brain }^{123} \text { I Activity) (Blood Withdrawal Rate) }}{\text { (Blood }{ }^{123} \text { I Activity) }}
$$

The regional scopolamine binding rate $\mathrm{k}_{3}$ was determined from the tissue $\left[{ }^{3} \mathrm{H}\right]$ scopolamine content, the integrated plasma $\left[{ }^{3} \mathrm{H}\right]$ scopolamine concentration (eq 3), and regional cerebral blood flow (eq 4), according to eq 1 . The cerebral PS for scopolamine was assumed to be 0.12 $\mathrm{ml} \mathrm{plasma/g} \mathrm{brain/min} \mathrm{as} \mathrm{determined} \mathrm{in} \mathrm{prior} \mathrm{studies} \mathrm{(4).}$

Materials. Labeled scopolamine was obtained by custom tritiation from Amersham (Arlington Hts., IL) and was adjusted to a specific activity of $30 \mathrm{Ci} / \mathrm{mmol}$ with unlabeled scopolamine.

Radioiodonated HIPDM was produced by exchange labeling (6) with the use of [ ${ }^{123}$ I] NaI obtained from Crocker Laboratories (Davis, CA). Atropine sulfate, scopolamine hydrochloride, and DFP were purchased from Sigma (St. Louis, MO).

\section{RESULTS}

Relationship of Equilibrium In Vivo Distribution to In Vitro Binding of $\left[{ }^{3} H\right]$ Scopolamine. The autoradiographic results of total in vivo $\left[{ }^{3} \mathrm{H}\right]$ scopolamine binding were compared with those following ex vivo removal of unbound tracer (in vivo specific binding) and with in vitro $\left[{ }^{3} \mathrm{H}\right]$ scopolamine binding. As expected, brief washing of the tissue following in vivo infusion of $\left[{ }^{3} \mathrm{H}\right]$ scopolamine reduced estimates of ligand binding in most brain regions. An unanticipated finding was that the apparent activity in brain regions with highest binding (subregions CA1 and the dentate gyrus of the hippocampal formation, striatum, and cerebral cortex) increased following washing (Figure 1). The relationships between in vivo total or specific binding and in vitro [ $\left.{ }^{3} \mathrm{H}\right] \mathrm{j}$ copolamine binding each support a predominant effect of muscarinic receptor concentration on in vivo accumulation of ligand under the equilibrium experimental conditions, with a minor contribution from nonspecific binding and free ligand.

Muscarinic Receptor Changes In Vitro Following Chronic Acetylcholinesterase Inhibition. Following one week of acetylcholinesterase inhibition by DFP, regional brain muscarinic receptor binding was significantly reduced in several areas (Table 1). Most affected were the cerebral cortex, the hippocampal formation, the striatum, the basolateral amygdala, and the nuclei of the facial and hypoglossal nerves. Other regions demonstrated only slight reduction or no change in binding with the exception of the substantia nigra pars reticulata, where a trend towards increased binding was observed.

Detection of Receptor Changes by Equilibrium In Vivo $\left[{ }^{3} H\right]$ Scopolamine Binding. As observed in in vitro autoradiographic assays, the equilibrium in vivo binding of $\left[{ }^{3} \mathrm{H}\right]$ scopolamine was significantly reduced in specific brain regions following DFP treatment. The reductions in total in vivo accumulation of scopolamine (Table II) were qualitatively similar to those in specific in vivo binding, following ex vivo washing of tissue sections (data not shown). The regional patterns and magnitudes of receptor changes were in good agreement between the equilibrium in vivo and the in vitro assays.

Effects of Chronic Acetylcholinesterase Inhibition and of Acute Atropine Treatment on Kinetic Receptor Binding Estimates. Regional cerebral blood flow was decreased approximately 15 to $35 \%$ by chronic administration of DFP in all regions examined (Table III). Reductions in the $\mathrm{k}_{3}$ estimates for $\left[{ }^{3} \mathrm{H}\right]$ scopolamine of approximately $50 \%$ were observed in the cerebral cortex, striatum, and hippocampus (Table IV). In the cerebellum, kinetic binding estimates were reduced by comparison to controls, however, the magnitude of the change was minor by comparison to the forebrain regions. Cerebral cortical kinetic binding estimates expressed relative to the cerebellum reveal substantial reductions following DFP treatment, suggesting a differentially 

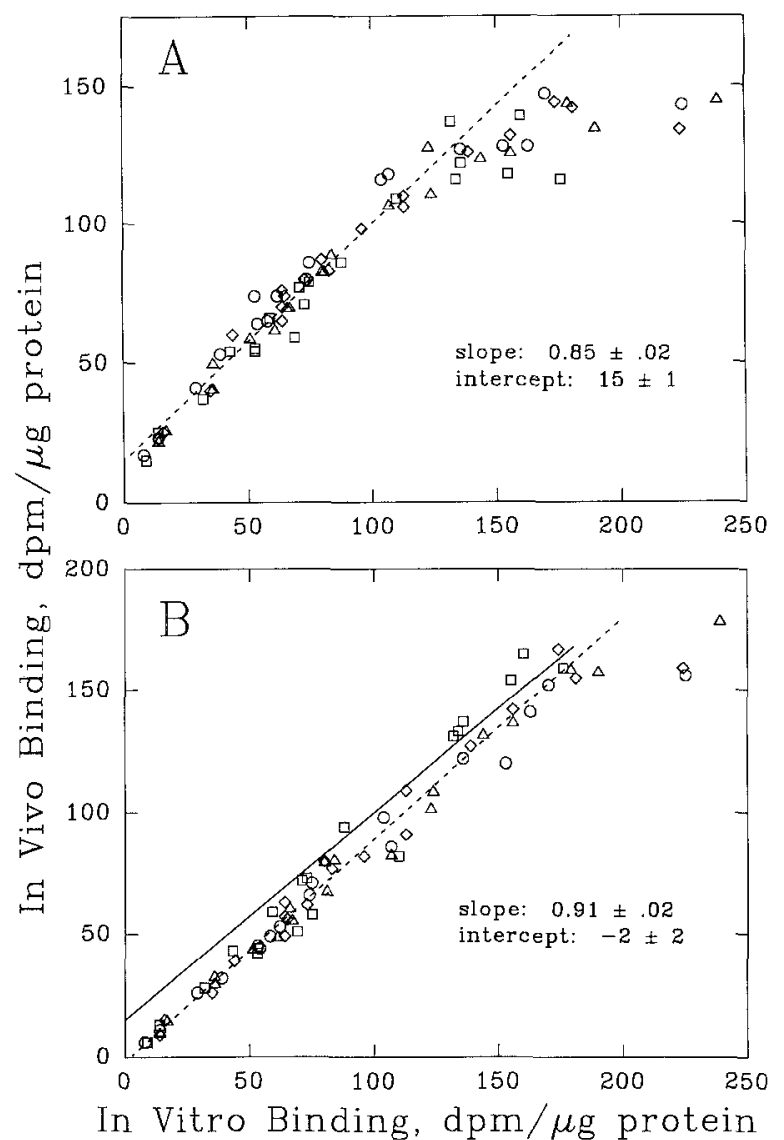

Fig. 1. Comparisons of total and specific in vivo binding with in vitro binding of scopolamine. A. Total in vivo binding of $\left[{ }^{3} \mathrm{H}\right]$ scopolamine versus in vitro binding as determined by quantitative autoradiography from adjacent brain sections in 4 subjects (designated by $\square, \Delta, \diamond$, and 0 ). Apparent isotope concentrations for regions listed in Table I are plotted. The linear relationship between the measures for structures with in vitro binding less than $150 \mathrm{dpm} / \mu \mathrm{g}$ protein is given by the dashed line. B. Specific in vivo $\left[{ }^{3} \mathrm{H}\right]$ scopolamine binding versus in vitro binding as determined by quantitative autoradiography. Measurements are taken from autoradiograms of sections immediately adjacent to those used in A, following washing to reduce nonspecific binding. The linear relationship between the measures for structures with in vitro binding less than $200 \mathrm{dpm} / \mu \mathrm{g}$ protein is given by the dashed line. The relationship determined in $\mathrm{A}$ is plotted for comparison (solid line). Note the relative downward shift and increase in slope produced by ex vivo washing of the tissue sections. In addition, there is differential enhancement of apparent activity in structures with highest receptor density, corresponding to the cerebral cortex, hippocampus, and striatum.

greater effect on the forebrain regions than on cerebellar binding.

Acute administration of a saturating dose of atropine resulted in small increases in CBF and large reductions in muscarinic receptor binding estimates, the latter ranging between 90 to $95 \%$ in the forebrain regions and over $75 \%$ in the cerebellum. Thus, most of the kineti-
Table I. Effect of Chronic DFP Treatment on In Vitro Muscarinic Receptor Binding

\begin{tabular}{lcc}
\hline \multicolumn{1}{c}{ Brain Region } & Control & DFP \\
\hline Frontal Cortex & $2.08 \pm .07$ & $1.54 \pm .05^{2}$ \\
Striatum & $2.54 \pm .13$ & $1.67 \pm .08^{2}$ \\
Hippocampus: CA1 & $3.24 \pm .41$ & $2.68 \pm .08$ \\
$\quad$ CA3 & $1.61 \pm .23$ & $1.29 \pm .06$ \\
$\quad$ Dentate Gyrus & $2.61 \pm .23$ & $2.05 \pm .07^{1}$ \\
Lateral Septal N. & $1.16 \pm .09$ & $0.89 \pm .13$ \\
Globus Pallidus & $0.23 \pm .02$ & $0.23 \pm .02$ \\
Ventral Ant. Thalamus & $0.61 \pm .06$ & $0.60 \pm .03$ \\
Corticomedial Amygdala & $1.16 \pm .07$ & $0.92 \pm .06^{1}$ \\
Basolateral Amygdala & $2.26 \pm .14$ & $1.61 \pm .07^{2}$ \\
Ventral Post. Thalamus & $0.94 \pm .04$ & $0.86 \pm .03$ \\
Lateral Geniculate & $0.89 \pm .11$ & $0.79 \pm .04$ \\
Medial Geniculate & $0.83 \pm .09$ & $0.76 \pm .11$ \\
Substantia Nigra R. & $0.50 \pm .05$ & $0.61 \pm .07^{1}$ \\
Periaqueductal Gray & $0.95 \pm .07$ & $0.82 \pm .04$ \\
Basal Pontine Nuclei & $1.78 \pm .17$ & $1.60 \pm .18$ \\
Cerebellar Cortex & $0.17 \pm .05$ & $0.15 \pm .02$ \\
Facial Nucleus & $1.15 \pm .06^{3}$ & $0.90 \pm .17$ \\
Hypoglossal Nucleus & $1.91 \pm .09^{3}$ & $0.84 \pm .14^{2}$ \\
\hline
\end{tabular}

Values represent the mean \pm SD of observations from four subjects in each group, expressed in $\mathrm{fmol} / \mu \mathrm{g}$ protein.

${ }^{1} \mathrm{p}<0.05$ by Student's $t$ test.

${ }^{2} \mathrm{p}<0.001$ by Student's $t$ test.

$3_{\mathrm{n}}=3$ subjects.

Table II. Effect of Chronic DFP Treatment on Equilibrium $\left[{ }^{3} \mathrm{H}\right]$ Scopolamine Binding In Vivo

\begin{tabular}{lcc}
\hline \multicolumn{1}{c}{ Brain Region } & Control & DFP \\
\hline Frontal Cortex & $1.85 \pm .07$ & $1.41 \pm .06^{2}$ \\
Striatum & $2.08 \pm .11$ & $1.57 \pm .09^{1}$ \\
Hippocampus: CA1 & $2.02 \pm .20$ & $1.85 \pm .25$ \\
$\quad$ CA3 & $1.59 \pm .20$ & $1.28 \pm .07$ \\
$\quad$ Dentate Gyrus & $2.03 \pm .19$ & $1.70 \pm .07$ \\
Lateral Septal N. & $1.27 \pm .08$ & $1.15 \pm .07$ \\
Globus Pallidus & $0.37 \pm .02$ & $0.38 \pm .04$ \\
Ventral Ant. Thalamus & $0.81 \pm .06$ & $0.84 \pm .05$ \\
Corticomedial Amygdala & $1.19 \pm .09$ & $0.99 \pm .01^{1}$ \\
Basolateral Amygdala & $1.91 \pm .06$ & $1.42 \pm .02^{2}$ \\
Ventral Post. Thalamus & $1.07 \pm .07$ & $0.99 \pm .06$ \\
Lateral Geniculate & $0.97 \pm .11$ & $0.92 \pm .04$ \\
Medial Geniculate & $0.95 \pm .13$ & $0.88 \pm .08$ \\
Substantia Nigra R. & $0.60 \pm .03$ & $0.73 \pm .07^{1}$ \\
Periaqueductal Gray & $0.98 \pm .10$ & $0.92 \pm .07$ \\
Basal Pontine Nuclei & $1.85 \pm .18$ & $1.86 \pm .05$ \\
Cerebellar Cortex & $0.29 \pm .06$ & $0.31 \pm .03$ \\
Facial Nucleus & $1.21 \pm .03^{3}$ & $1.02 \pm .17$ \\
Hypoglossal Nucleus & $1.57 \pm .09^{3}$ & $0.98 \pm .08^{2}$ \\
\hline
\end{tabular}

Values represent the mean \pm SD of observations from four subjects in each group, expressed in $\mathrm{fmol} / \mu \mathrm{g}$ protein.

${ }^{1} \mathrm{p}<0.05$ by Student's $t$ test.

${ }^{2} \mathrm{p}<0.001$ by Student's $t$ test.

${ }^{3} \mathrm{n}=3$ subjects. 
Table III. Effects of Chronic DFP and of Acute Atropine Treatments on Regional Cerebral Blood Flow

\begin{tabular}{lccc}
\hline Brain Region & Control & DFP & Atropine \\
\hline & $(n=6)$ & $(n=3)$ & $(n=3)$ \\
Frontal Cortex & $1.1 \pm .3$ & $0.7 \pm .1$ & $1.2 \pm .1$ \\
Striatum & $0.9 \pm .2$ & $0.6 \pm .^{1}$ & $1.2 \pm .1$ \\
Hippocampus & $0.7 \pm .1$ & $0.5 \pm .1^{1}$ & $0.7 \pm .1$ \\
Cerebellum & $0.8 \pm .1$ & $0.5 \pm .1$ & $1.1 \pm .2$ \\
\hline
\end{tabular}

Values represent the mean \pm S.D. of regional cerebral blood flow determinations expressed as $\mathrm{ml}$ blood $/ \mathrm{g}$ brain/min.

${ }^{1} \mathrm{p}<0.05$ versus control by pairwise Scheffe tests, following significant $(\mathrm{p}<0.05)$ one-way ANOVA.

cally-estimated ligand binding in the control and DFPtreated groups is attributable to muscarinic receptor availability.

\section{DISCUSSION}

Relationship of In Vivo and In Vitro Equilibrium Receptor Binding. The present study extends prior observations on the equilibrium binding application of labeled scopolamine for measurement of cerebral muscarinic receptor availability in vivo. It has been previously determined that the relationship between total scopolamine binding in vivo and in vitro estimates of muscarinic receptors made with $\left[{ }^{3} \mathrm{H}\right]$ quinuclidinyl benzilate are highly correlated, and that there is a component suggestive of the presence of nonspecific binding and free ligand under in vivo conditions $(2,3)$. In the present studies, this speculation has been confirmed following ex vivo washing of tissue to reduce the contribution of nonspecific binding. Following washing, the relationship between in vivo and in vitro binding is linear with an intercept at the origin.
An unexpected additional finding in these studies is the apparent increase in ligand concentration following washing of the tissue, particularly evident in brain regions with greatest receptor densities. Several of these regions appear to deviate from the linear relationship between total binding in vivo and in vitro determined for regions of low to moderate receptor concentration. The apparent underestimation of in vivo binding in these regions is not due to failure to fully equilibrate ligand binding, the presence of endogenous neurotransmitter, or other factors affecting the biodistribution of tracer, since post-washing of the labeled tissue restores linear correlation of the in vivo and in vitro binding estimates in these regions. It is unlikely that unbound tracer from distant regions is removed and then rebound to account for these changes, since the washing procedure was conducted in relatively large volumes of buffer (greater than $10 \mathrm{ml}$ per slide in each of two $5 \mathrm{~min}$ washes) and was conducted at $4^{\circ} \mathrm{C}$. An alternative is suggested by inspection of the linear regression slopes in the pre- and post-washing conditions. An increase in the slope relating in vivo to in vitro binding is seen even in the regions of low receptor concentration. In addition, the regression slope in the in vivo specific binding case is less than unity, suggesting that incubation of tissue for $30 \mathrm{~min}$ at $24^{\circ} \mathrm{C}$ produces an incremental effect. These observations suggest that incubation in buffer alters the self-absorption properties of the tissue sections, perhaps by elimination of salts, soluble proteins, or other attenuating factors. The differential effects noted in the cerebral cortex and hippocampal formation may be due to concentration of binding sites in subregions (lamina) with greatest loss of attenuating factors. Tissue attenuation effects on autoradiographic quantification of tritium have been previously documented in relation to regional differences in brain lipid content (10-12). The effect suggested by the present studies cannot be investigated in exclusively in

Table IV. Effects of Chronic DFP and of Acute Atropine Treatments on Tracer Kinetic Estimates of [ $\left.{ }^{3} \mathrm{H}\right]$ Scopolamine Binding In Vivo

\begin{tabular}{|c|c|c|c|c|c|c|}
\hline \multirow[b]{2}{*}{ Brain Region } & \multirow[b]{2}{*}{ Control } & \multirow[b]{2}{*}{ DFP } & \multirow[b]{2}{*}{ Atropine } & \multicolumn{3}{|c|}{ Binding Relative to Cerebellum ${ }^{1}$} \\
\hline & & & & Control & DFP & Atropine \\
\hline Frontal Cortex & $\begin{array}{c}(n=6) \\
0.14 \pm .05\end{array}$ & $\begin{array}{c}(\mathrm{n}=3) \\
0.05 \pm .01^{2}\end{array}$ & $\begin{array}{c}(\mathrm{n}=3) \\
0.007 \pm .004^{3}\end{array}$ & $\begin{array}{c}(n=6) \\
4.3 \pm 1.0\end{array}$ & $\begin{array}{c}(n=3) \\
2.3 \pm 0.3^{2}\end{array}$ & $\begin{array}{c}(n=3) \\
1.1 \pm .03^{2}\end{array}$ \\
\hline Striatum & $0.09 \pm .04$ & $0.04 \pm .01$ & $0.007 \pm .005^{2}$ & $2.7 \pm 0.9$ & $1.7 \pm 0.1$ & $1.0 \pm 0.4^{2}$ \\
\hline Hippocampus & $0.08 \pm .02$ & $0.04 \pm .01^{2}$ & $0.008 \pm .006^{3}$ & $2.4 \pm 0.3$ & $2.1 \pm 0.2$ & $1.2 \pm 0.3^{3}$ \\
\hline Cerebellum & $0.03 \pm .01$ & $0.02 \pm .01^{2}$ & $0.007 \pm .004^{3}$ & & & \\
\hline
\end{tabular}

Values represent the mean $\pm \mathrm{SD}$ of kinetic binding estimates.

${ }^{1}$ Regional values expressed relative to the cerebellum from the corresponding subject.

${ }^{2} p<0.05$ by pairwise Scheffe test, following significant $(p<0.05)$ one-way ANOVA.

${ }^{3} p<0.01$ by pairwise Scheffe test, following significant $(p<0.05)$ one-way ANOVA. 
vitro studies, since in vivo labeling of the tissue is necessary for its detection. Thus, an additional caveat in interpretation of in vitro autoradiographic receptor determinations with tritiated ligands is suggested. The effect may contribute to minor differences in apparent receptor distribution between autoradiographic and tissue homogenate binding studies.

Effect of Chronic Acetylcholinesterase Inhibition on Muscarinic Receptors. The current studies are in good agreement with prior observations of reduced muscarinic receptors in the rat brain following inhibition of acetylcholinesterase. Treatment with DFP causes reduction in striatal (13) and in cortical (14) muscarinic receptors as quantified in homogenate binding assays. A prior study utilizing semi-quantitative tissue autoradiography following DFP treatment (15) found reductions in cerebral cortical, striatal, and hippocampal binding as in the present work. The prior results, however, suggest reductions in septal and pontine binding not evident in the present study. The reduction in hypoglossal nucleus and the small increase in substantia nigra receptor binding observed in the present work have not been previously reported. The reason for these discrepancies is uncertain, but may reside in differences in DFP administration schedules or in the methodology for quantification of autoradiographic binding. Nevertheless, the major findings of the investigations are in agreement that DFP treatment produces a loss of muscarinic receptor binding in forebrain areas with high densities of presynaptic cholinergic terminals. It is likely that this effect is indirectly mediated by increases in acetylcholine levels, since prior lesioning of presynaptic cholinergic terminals prevents neocortical receptor losses (14).

Comparison of Equilibrium and Tracer Kinetic Binding Methods. Results from both equilibrium and kinetic in vivo binding studies indicate the feasibility of detecting altered receptor populations. By comparison with the results of in vitro binding, neither in vivo method appears as sensitive, due to variability in the data. The equilibrium method results in better precision than the kinetic method, however, this may be partly attributed to differences in region identification and tissue sampling which tend to favor the autoradiographic equilibrium binding design. In addition, the kinetic calculation applied here may suffer from invalid assumptions concerning ligand transport. First, the determination of cerebral blood flow was made at the end of the $90 \mathrm{~min}$ $\left[{ }^{3} \mathrm{H}\right]$ scopolamine distribution period. Since effects of flow on ligand transport and binding are greatest immediately following bolus injection, changes in perfusion during the course of the experiment might lead to inaccurate correction for ligand transport. Second, and more sig- nificantly, since scopolamine transport is highly sensitive to PS, it may be incorrect to assume a constant value across experimental groups. A combination of these errors may underlie apparent loss of binding in the cerebellum in kinetic studies. It has been previously reported that PS varies in the same direction as cerebral blood flow during alterations in arterial $\mathrm{pCO}_{2}$ and following administration of antidepressants (16-18). Thus, PS may have been lower than assumed in the DFP-treated animals, leading to underestimation of binding in the kinetic experiments. This error alone may be sufficient to account for the small reduction in cerebellar binding, and may contribute to the greater magnitude of forebrain receptor losses in the kinetic as compared to the equilibrium experiments. On the basis of method precision and due to the considerations above, the equilibrium in vivo $\left[{ }^{3} \mathrm{H}\right]$ scopolamine binding method would appear most favorable for studies in experimental animals.

Implications for Clinical Receptor Imaging Studies. Clinical research quantification of muscarinic receptors may, in theory, be accomplished by application of PET imaging to the detection of scopolamine labeled with the positron emitting nuclide ${ }^{11} \mathrm{C}\left(\left[{ }^{11} \mathrm{C}\right]\right.$ scopolamine; 19,20$)$. On the basis of the foregoing comparison in experimental animals, the equilibrium approach might appear desirable for clinical measures as well. However, equilibrium imaging with labeled scopolamine requires saturating ligand levels over a several hour period. Both of these conditions are unobtainable due to the adverse clinical effects of high doses of scopolamine and to the short $(20$ $\min$ ) isotopic half-life of ${ }^{11} \mathrm{C}$. The tracer kinetic experimental design is thus the only available choice for such studies, and might yield results more precise than predicted by the current studies. The entire brain time-course of tracer activity may be obtained by dynamic PET imaging, eliminating the need for simplifying assumptions about initial ligand extraction, PS, and CBF. Thus, the physiologic accuracy and precision of clinical kinetic measures may exceed estimates derived from the current animal studies. In fact, measurements of muscarinic receptor binding with the kinetic $\left[{ }^{11} \mathrm{C}\right]$ scopolamine method have been achieved with PET in normal human volunteers (21). The present studies suggest the feasibility of detecting alterations in cortical and perhaps other regional receptor populations with this method.

\section{ACKNOWLEDGMENTS}

The authors acknowledge the efforts of Dr. Donald Wieland for his syntheses of $\left[{ }^{123} 1\right]$ HIPDM. This work was supported by grants 
designated 1-P01-MH42652 and 5-P01-NS15655 from the National Institutes of Health.

\section{REFERENCES}

1. Young, A. B., Frey, K. A., and Agranoff, B. W. 1986. Receptor assays: In vitro and in vivo, Pages 73-111, in Phelps, M., Mazziotta, J., and Schelbert, H. (eds.), Positron Emission Tomography and Autoradiography: Principles and Applications for the Brain and Heart, Raven Press, New York.

2. Frey, K. A., Ehrenkaufer, R. L. E., Beaucage, S., and Agranoff, B. W. 1985. Quantitative in vivo receptor binding I. Theory and application to the muscarinic cholinergic receptor. J. Neurosci. $5: 421-428$.

3. Frey, K. A., Ehrenkaufer, R. L. E., and Agranoff, B. W. 1985. Quantitative in vivo receptor binding II. Autoradiographic imaging of muscarinic cholinergic receptors. J. Neurosci. 5:2407-2414.

4. Frey, K. A., Hichwa, R. D., Ehrenkaufer, R. L. E., and Agranoff, B. W. 1985. Quantitative in vivo receptor binding III: Tracer kinetic modeling of muscarinic cholinergic receptor binding. Proc. Natl. Acad. Sci. USA 82:6711-6715.

5. Pan, H. S., Frey, K. A., Young, A. B., and Penney, Jr., J. B. 1983. Changes in $\left[{ }^{3} \mathrm{H}\right]$ muscimol binding in substantia nigra, entopeduncular nucleus, globus pallidus, and thalamus after striatal lesions as demonstrated by quantitative receptor autoradiography. J. Neurosci. 3:1189-1198.

6. Kung, H. F., Tramposch, K. M., and Blau, M. 1983. A new brain perfusion imaging agent: [I-123]HIPDM:N,N,N'-trimethyl$N^{\prime}$-[2-hydroxy-3-methyl-5-iodobenzyl]-1,3-propanediamine. J. Nucl. Med. 24:66-72.

7. Lucignani, G., Nehlig, A., Blasberg, R., Patlack, C. S., Anderson, L., Fieschi, C., Fazio, F., and Sokoloff, L. 1985. Metabolic and kinetic considerations in the use of [ ${ }^{125}$ I]HIPDM for quantitative measurement of regional cerebral blood flow. J. Cereb. Blood Flow Metabol, 5:86-96.

8. Goldman, H., and Sapirstein, L. A. 1973. Brain blood flow in the conscious and anesthetized rat. Am. J. Physiol. 224:122-126.

9. Van Uitert, R. L., and Levy, D. E. 1978. Regional brain blood flow in the conscious gerbil. Stroke 9:67-72.

10. Alexander, G. M., Schwartzman, R. J., Bell, R. D., Yu, J., and Renthal, A. 1981. Quantitative measurement of local cerebral metabolic rate for glucose utilizing tritiated 2-deoxyglucose. Brain Res. 223:59-67.

11. Herkenham, M., and Sokoloff, L. 1984. Quantitative receptor autoradiography: Tissue defatting eliminates differential self-absorption of tritium radiation in gray and white matter of brain. Brain Res. 321:363-368.

12. Geary, W. A., II, and Wooten, G. F. 1985. Regional tritium quenching in quantitative autoradiography of the central nervous system. Brain Res. 336:334-336.

13. Ehlert, F. J., Koka, N., and Fairhurst, A. S. 1979. Altered $\left[{ }^{3} \mathrm{H}\right]-$ quinuclidinyl benzilate binding in the striatum of rats following chronic cholinesterase inhibition with diisopropylflourophosphate. Mol. Pharmacol. 17:24-30.

14. McKinney, M., and Coyle, J. T. 1982. Regulation of neocortical muscarinic receptors: effects of drug treatment and lesions. J. Neurosci. 2:97-105.

15. Churchill, L., Pazdernik, T. L., Samson, F., and Nelson, S. R. 1984. Topographical distribution of down-regulated muscarinic receptors in rat brains after repeated exposure to diisopropyl phosphorofluoridate. Neuroscience 11:463-472.

16. Phelps, M. E., Huang, S.-C., Hoffman, E. J., Selin, C., and Kuhl, D. E. 1981. Cerebral extraction of N-13 ammonia: Its dependence on cerebral blood flow and capillary permeability-surface area product. Stroke 12:607-619.

17. Preskorn, S. H., Hartman, B. K., Raichle, M. E., and Clark, H. B. 1980. The effect of dibenzazapines (tricyclic antidepressants) on cerebral capillary permeability in the rat in vivo. J. Pharmacol. Exp. Ther. 213:313-320.

18. Preskorn, S. H., Irwin, G. H., Simpson, S., Friesen, D., Rinne, J., and Jerkovich, G. 1981. Medical therapies for mood disorders alter the blood-brain bartier. Science 213:469-471.

19. Vora, M. M., Finn, R. D., Boothe, T. E., Liskowsky, D. R., and Potter, L. T. 1983. [N-methyl- $\left.{ }^{11} \mathrm{C}\right]$-scopolamine: Synthesis and distribution in rat brain. J. Labelled Compd. Radiopharm. 20:1229-1236.

20. Mulholland, G. K., Jewett, D. M., and Toorongian, S. A. 1988. Routine synthesis of $\mathrm{N}-\left[{ }^{11} \mathrm{C}\right.$-methyl $]$ scopolamine by phosphite mediated reductive methylation with $\left[{ }^{11} \mathrm{C}\right]$ formaldehyde. Appl. Radiat. Isot. 39:373-379.

21. Frey, K. A., Koeppe, R. A., Mulholland, G. K., Jewett, D., Hichwa, R., Ehrenkaufer, R. L. E., Carey, J. E., Wieland, D. M., Kuhl, D. E., and Agranoff; B. W. 1991. In vivo muscarinic cholinergic receptor imaging in human brain with $\left[{ }^{11} \mathrm{C}\right]$ scopolamine and positron emission tomography. J. Cereb. Blood Flow Metab. In Press. 